\title{
Ethical dilemma in Bioethics education: Interns' personal experience narratives
}

\author{
Ishani Patel ${ }^{1}$, Jalpan Patel ${ }^{2}$, Hetvi Tanna ${ }^{3}$, Barna Ganguly ${ }^{4}$ \\ ${ }^{1,2}$ Intern \\ ${ }^{2} 2^{\text {nd }}$ MBBS student \\ ${ }^{3}$ Professor, Department of Pharmacology, Head - UNESCO Bioethics Unit, Gujarat. \\ 1,2,3 Pramukhswami Medical College, Karamsad, Gujarat. \\ Corresponding Author : Barna Ganguly \\ E-mail: barnaganguly@rediffmail.com
}

\begin{abstract}
Students are learning the science of physical examination and procedures during their training, but very less are taught the softer skill of doctor patient relationship or the art of empathy and humanity. Over the last few years, bioethics teaching is being introduced and carried out in a few Indian Medical Colleges. However, teaching Bioethics in classrooms does not serve the purpose unless ethics in real life situations is actively discussed and practiced during the training of medical students. But, educational experiences of the students and Interns during their course pose conflict between ethics education and dilemma in learning process related to specific gaps between what they are taught and what is being practiced
\end{abstract}

Key words: Bioethics teaching, practice

\section{INTRODUCTION}

Bioethics is a relatively new term coined by a biochemist, Van Rensselaer Potter, in 1970 in an endeavour to draw attention to the fact that the rapid advances in science had proceeded without due attention being paid to values. Potter said that he coined the word bioethics using two Greek words, bios, life, representing the facts of life and life sciences, and éthos, morals, referring to values and duties. He conceived this new discipline, bioethics, as a 'bridge' between 'facts' and 'values'. During the second half of the twentieth century, he said that biological sciences had been increasing their knowledge and technical power continuously, but reflection about the values at stake has not progressed in the same proportion [1].

Bioethics is related with every practicing doctor's day to day duty. Medical practice includes a moral component, in the form of duty to his or her patient or in clinical decision-making. Clinicians are facing moral dilemmas in regular practice. There have been continuing demands for the renewal of medical education [2-3]. Social considerations in medicine demand a long term perspective on human relationships requiring knowledge about human nature, family culture, and social welfare. Thus, it has now been recognized as an important component in medical education [4]. There has to be a focus on classical dilemmas and a textbook knowledge of principles is yielding its previous dominance to permit a more detailed examination of ethical behavior in actual practice in medicine [5]. Over the last few years, bioethics teaching is being introduced and carried out in a few Indian Medical Colleges. However, teaching Bioethics in classrooms does not serve the purpose unless ethics in real life situations is actively discussed and practiced during the training of medical students. Students are learning the science of physical 
examination and procedures during their training, but very less are taught the softer skill of doctor patient relationship or the art of empathy and humanity [6]. But, educational experiences of the students and Interns in demonstrating knowledge, skills, and attitudes in professionalism and ethics are found to be insufficient to meet the real life ethical challenges experienced in actual practice [7].

Medical students face a number of ethical issues during their clinical rotations in the hospital arising from the reality. Several questions emerge in their mind in course of training when they are coming to learn about various ethical principles. Henceforth, starts the beginning of ethical dilemma and conflicts in their mind. Below are two such dilemmas by the interns in the form of personal experience narratives [8].

\section{NARRATIVE 1 - The Cross Road}

Hema, while pursuing her Bachelors in paramedical courses got into live-in-relationship and became pregnant at the age of 19 years. She was very tensed and worried, so called one of her friends, Dhara, doing internship in MBBS course.

Hema said "Dhara, Please help me! How can I come out of this situation?" Dhara thought for a while, she was not in a position to either prescribe some drug to abort the foetus. She was absolutely confused, her conscious was inhibiting her, reminded her of the class on morals to kill or harm someone who is not yet born in one hand, and wishing to help her friend, Hema who was in a difficult time on the other hand. Suddenly she remembered, "Why not to talk to Dr. Urmila Shah? She, being our teacher, will surely help!" Dhara took Hema to the Gynecologist, Dr. Urmila and narrated the whole story.

After listening, Dr. Urmila told, "I can't give pills as such, it could even harm the mother. You have to undergo some investigations and once it is confirmed from the investigations, I can perform further treatment". After hearing all this, Hema refused to undergo for so many investigations in the hospital as she didn't want her identity to be revealed. Earlier, Hema witnessed other scenarios of how the staff members kept discussing of such type of cases, and she was afraid of being humiliated! She was thinking, ".... Hospital is a place where patient should feel comfortable ..... and..... I can't even share this to my colleagues and come to the hospital .... they will laugh at me..... what a grave mistake have I done ... for which I cant show my face to any anyone ..... can't they understand how much I am suffering? from such a situation?" Finally Hema went to another Gynaecologist practicing privately. She, without going through proper checkup, without advising the consequences of the pills, and without any counseling, treated Hema by charging double fees. Hema was helpless and thought "Finally this is my destiny!, I have to pay for my err". One day, in a case discussion session in the department, Dr. Urmila referred the case of Hema revealing her name, who was well known with other students and a few staff members. Dhara was also present and taking part in the case discussion. The ethical issues related to that incidence were taken up and discussed.

A lot of thoughts came to Dhara's mind, "What is ethics that we are learning in a class, where my friend is being exposed badly in a teaching session?" ........ "Is it that Second Gynecologist took the advantage of Hema's situation? Was it a right way to treat in such a situation?" ...... "Is it our social and cultural matters influencing our profession?"

From the above narrative by the Interns, it is evident that dignity and respect and also confidentiality, which are essential for the doctor patient relationship, are missing from students' experiences of learning medicine. The Interns were witnessing the gap between teaching and practice and preaching as well. This is producing a terrible stressed environment in the mind of students and interns. Thus it seems that ensuring high ethical standards in medical education is a difficult task.

\section{NARRATIVE 2 - Can't I get the same scope of learning ?}

As a medical student I was always eager in learning new things practically. When I was posted in Obstretrics and Gynaecology Department, I was the only boy, in a group of 5 students. 
Once on a regular OPD day, there was a patient diagnosed to have some rare disease. I don't remember the disease as I didn't get chance to see her. As per usual custom, during examination of a female patient, there is a resident along with a student in the OPD. It was an unusual case, so the resident told all of us to see the patient. As soon as all the girls entered, the patient felt a bit uncomfortable to be examined by the students. But the resident counseled her of the fact that she was in a medical college hospital which is also a place for students to learn medical science. So the patient sat quietly. But when I entered the room, the patient was enraged seeing me, a male. She immediately told to stop the examination as she didn't want herself to be exposed in front of a male student. The resident got angry and I was told to be off from the room. I felt deducted.

I understand that being in a medical field, assimilating knowledge is most important but the situations don't allow me doing that. How am I as a medical student? Is it like I am going to be a clinician with less hands on experience? Is it only girls who are privileged enough to gain hands on skill in that department???....

An exploratory survey reported by a final year medical students clearly shows that medical students and clinical teachers, even in the developed world, tend to take their patients for granted [9]. This narrative is reflecting an ethical dilemma in students' mind on justice in medical education. The teaching of physical examinations and acquiring skills in procedures poses ethical problems for students and educators. In one hand, students must learn, but on the other side patients must be protected. Several questions emerge in the minds of medical trainee during their course like conflict between medical education and patient care, dilemma in involvement in care as a student and more so, the specific gaps between what they are taught and what is being practiced.

To develop ethical training in teaching hospitals, clinical teachers would have to play a major role now. They must supervise students accordingly based on risk assessment educate patients about the benefits of student participation in medical care, and their role in training the next generation of physicians. Treating patients with respect and asking permission before doing any examination, tests, or procedures can help establish good doctor-patient relationship. Role modeling must have some impact on our students. So in the face of this eroding clinical environment, it is necessary to preserve the best qualities of the medical profession to make sure that there is a faculty who can take good care of patients and be role models for students [10]. Also, because patients play a major role in shaping our education, and lend their body to do so, we must acknowledge their contribution in our training with gratitude.

\section{REFERENCES}

1. Teacher Manual. The birth of bioethics : UNESCO Bioethics Core Curriculum, 2005.

2. World Health Organization. The Edinburgh Declaration. Med Educ 1988;22:481-2.

3. Wiedersheim R. Medical education - too little care, too much intervention. Nord Med 1978;93:216-9.

4. Eckles RE, Meslin EM, Gaffney M,Helft PR. Medical ethics education: where are we? Where should we be going? A review. Acad Med 2005;80(12):1143-52.

5. Hundert EM, Douglas-Steele D, Bickel J. Context in medical education: the informal ethics curriculum. Med Educ 1996;30(5):353-64.

6. Kalantri SP. Ethics in Medical Education. Indian J Anaesth 2003;47(6):435-6.

7. Kesselheim JC, Johnson J, Joffe S. Pediatricians' reports of their education in ethics. Arch Pediatr Adolesc Med 2008;162(4):368-73.

8. Pandya R, Shukla R, Gor AP, Ganguly B. Personal experience narratives by students: a teachinglearning tool in bioethics Indian J Med Ethics 2016;1(3):144-7.

9. Doyal L. Closing the gap between professional teaching and practice. BMJ 2001;322:685-6.

10. Ozuah PO. Undergraduate medical education: Thoughts on future challenges. BMC Medical Education 2002;2:8

$$
\text { Acknowledgements - Nil ; Source of Funding - Nil ; Conflict of Interest - Nil }
$$

